\title{
Nano copper ferrite: A reusable catalyst for the synthesis of $\beta, \gamma$-unsaturated ketones
}

\author{
Y L N MURTHY $^{\mathrm{a}, *}$, B S DIWAKAR ${ }^{\mathrm{a}}$, B GOVINDH $^{\mathrm{a}}, \mathrm{K}^{\mathrm{N}}$ NAGALAKSHMI $^{\mathrm{a}}$, \\ I V KASI VISWANATH ${ }^{\mathrm{b}}$ and RAJENDRA SINGH ${ }^{\mathrm{c}}$ \\ ${ }^{a}$ Organic Research Labs, Department of Organic Chemistry, Andhra University, Visakhapatnam 530 003, India \\ ${ }^{b}$ Department of Chemistry, K L University, Greenfields Vaddeswaram, Guntur 522 502, India \\ ${ }^{\mathrm{c}}$ Defence Research and Development Organization (ER\&IPR), Rajaji Marg, New Delhi 110 011, India \\ e-mail: murthyyln@gmail.com
}

MS received 24 April 2011; revised 9 November 2011; accepted 20 December 2012

\begin{abstract}
Copper ferrite nano material as reusable heterogeneous initiator in the synthesis of $\beta, \gamma$ unsaturated ketones and allylation to acid chlorides are presented. The reaction of allylichalides with various acid chlorides is achieved in the presence of copper ferrite nano powders at room temperature in tetrahydrofuran (THF). The present method is first of its kind in the synthesis of title compounds without any additive/ co-catalyst. The nano catalyst is easily recovered and its reusability is recorded.
\end{abstract}

Keywords. Nano copper ferrite; heterogeneous initiator; allylation; $\beta, \gamma$-unsaturated ketones; reusability.

\section{Introduction}

Despite the advantages of homogeneous metal catalysts, difficulties in recovering the catalyst from the reaction mixture severely inhibit their use in industry. Heterogeneous catalysis results in easy separation and recycling of catalyst. Recent reports reveal that magnetic nanoparticles are efficient catalysts and they can be easily separated from reaction mixture. ${ }^{1}$ The high surface area to volume ratio of metal oxide nanoparticle is mainly responsible for their catalytic performance. ${ }^{2}$ Copper ferrite nano material is one such reusable catalyst which shows profound catalytic activity in organic synthesis. ${ }^{3}$

$\beta, \gamma$-Unsaturated ketones are versatile synthons in the synthesis of natural products. ${ }^{4}$ In general acylation of olefins produces $\beta, \gamma$-unsaturated ketones, but $\alpha, \beta$ unsaturated ketones may also be generated. ${ }^{5}$ The synthesis is complicated by a tendency towards prototropic rearrangement producing conjugated $\alpha, \beta$-unsaturated ketones. ${ }^{6}$ Allyl ketones are prepared by the reaction of various allylic organometallics ${ }^{7}$ with acyl halides but these reactions are of limited applications. Cadmium $^{8}$, zinc ${ }^{9}$ and indium ${ }^{10}$ are some of the transition metal powders reported earlier to synthesize these $\beta$, $\gamma$-unsaturated ketones but the processes employed are tedious and time taking. Thus it is clearly evident that the need for the development of new and flexible protocols is required in such a way that they should be

*For correspondence more economic and environmentally benign. Here in, we report nano copper ferrite as a reusable catalyst, for the allylation of acid chlorides with shorter reaction times (than reported) in good to moderate yields. The general synthetic scheme is presented in scheme 1.

\section{Synthetic procedures}

\subsection{Preparation of the nano catalyst}

The catalyst was synthesized by citrate gel precursor method. ${ }^{11}$ Copper (II) nitrate and iron (III) nitrate were taken in stoichiometric proportions and minimum amount of deionized water was added to produce clear cationic solution. Citric acid solution was then prepared in stoichiometric ratio. Aqueous solutions with 1:1 molar ratio of metal ion solutions were mixed and citric acid was added in equimolar ratio to the above mixed metal ion solution. $\mathrm{pH}$ was adjusted to 7 by adding ammonia solution. The aqueous mixture was kept for stirring to form a highly viscous gel. The gel was then heated gradually up to $90^{\circ} \mathrm{C}$ to evolve reddish brown gases and became dried gel which was finally treated at $350^{\circ} \mathrm{C}$ for $1 \mathrm{~h}$ to observe whether the dry gel burnt out in self propagating manner to form loose powder. The finely powdered particles were calcinated at $600^{\circ} \mathrm{C}$. The powder was then characterized.

\subsection{General synthesis of $\beta, \gamma$-unsaturated ketone $3 a$}

In a typical procedure, allyl bromide $(1 \mathrm{mmol})$ in absolute THF $(5 \mathrm{ml})$ was added to a stirring suspension of 


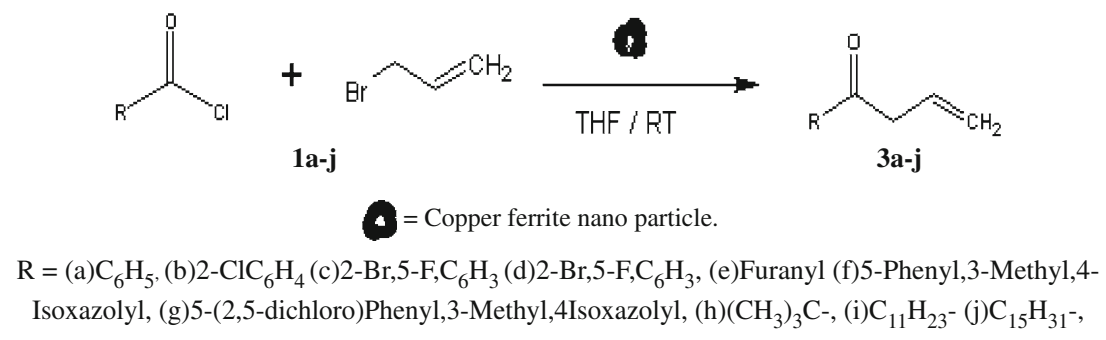

Scheme 1. Synthesis of $\beta, \gamma$-unsaturated ketone using allyl bromide.

copper nano ferrite $(10 \mathrm{~mol} \%)$ and stirring was continued for $30 \mathrm{~min}$ at room temperature. Benzoyl chloride $(1 \mathrm{mmol})$ was then added in THF $(10 \mathrm{ml})$ to the reaction mixture and then the reaction was continued for a certain period of time as required for completion (monitored by TLC). The reaction mixture was then filtered to separate the catalyst and the filtrate was quenched with a few drops of water and the product was extracted with dichloromethane and the solvent was removed under reduced pressure. Further purification was attained by column chromatography, a colourless crystalline compound was formed and recrystalized from ethanol. The pure compound was then characterized. Spectral data of selected compounds are given below.

2.2a 1-Phenyl but-3-en-1-one (table 4 entry 1)3a: ${ }^{12} \mathrm{IR}$ $\left(v_{\max }, \mathrm{KBr}\right.$ Pellet in $\left.\mathrm{cm}^{-1}\right): 1701(-\mathrm{C}=\mathrm{O}), 1669(-\mathrm{C}=\mathrm{C}-)$, 3009 (=C-H); ${ }^{1} \mathrm{HNMR}$ (90 MHz, $\left.\mathrm{CDCl}_{3} / \mathrm{TMS}\right)$ : 7.258.4 $(\mathrm{ArH}, \mathrm{m}), 3.89(2 \mathrm{H}, \mathrm{d}), 5.82-6.09(1 \mathrm{H}, \mathrm{m}), 5.09-$ $5.39(2 \mathrm{H}, \mathrm{d} / \mathrm{d}) ;{ }^{13} \mathrm{C}$ NMR $\left(22.5 \mathrm{MHz}, \mathrm{CDCl}_{3} / \mathrm{TMS}\right)$ \$171.94, 133.77, 130.2,129.4, 128.41,105.07, 42.28.

2.2b 1-(2-Chloro phenyl) but-3-en-1-one (table 4 entry 2) 3b: IR $\left(v_{\max }, \mathrm{KBr}\right.$ Pellet in $\left.\mathrm{cm}^{-1}\right): 1715(-\mathrm{C}=\mathrm{O})$, $1680(-\mathrm{C}=\mathrm{C}-), 3071$ (=C-H), $776(\mathrm{C}-\mathrm{Cl}))^{1} \mathrm{HNMR}(90 \mathrm{MHz}$, $\left.\mathrm{CDCl}_{3} / \mathrm{TMS}\right): \delta 7.41-7.93(\mathrm{~m}, \mathrm{ArH}), 3.33(\mathrm{~d}, 2 \mathrm{H}), 4.76$ $5.10(\mathrm{~m}, 1 \mathrm{H}), 4.22(\mathrm{~d} / \mathrm{d}, 2 \mathrm{H}) ;{ }^{13} \mathrm{CNMR}\left(22.5 \mathrm{MHz}, \mathrm{CDCl}_{3} /\right.$ TMS): $\delta 166.69,132.55,131.94,131.6,130.73,127.20$, 36.74 .

2.2c 1-(Furan-2-yl) but-3-en-1-one (table 4 entry 5) 3e: $\quad$ IR $\left(v_{\max }, \mathrm{KBr}\right.$ Pellet in $\left.\mathrm{cm}^{-1}\right): 1717(-\mathrm{C}=\mathrm{O}), 1648$ $(-\mathrm{C}=\mathrm{C}-), 3127$ (=C-H), 1077 (C-O-C); ${ }^{1} \mathrm{HNMR}(90 \mathrm{MHz}$, $\left.\mathrm{CDCl}_{3} / \mathrm{TMS}\right): \delta 7.53,7.33,6.78(\mathrm{~m}, 3 \mathrm{H}), 3.6(\mathrm{~d}, 2 \mathrm{H}), 6.57-$ $6.55(\mathrm{~m}, 1 \mathrm{H}), 4.365 .22(\mathrm{~d} / \mathrm{d}, 2 \mathrm{H}) ;{ }^{13} \mathrm{CNMR}(22.5 \mathrm{MHz}$, $\left.\mathrm{CDCl}_{3} / \mathrm{TMS}\right): \delta 178.28,162.32,147.19,143.92,119.39$, 112.21111.82, 27.67.

2.2d 1-(5-Methyl-3-phenyisoxazol-4-yl) but-3-en-1-one (table 4 entry 6) $3 f:{ }^{10} \mathrm{IR}\left(v_{\max }, \mathrm{KBr}\right.$ Pellet in $\left.\mathrm{cm}^{-1}\right): 1719$ $(-\mathrm{C}=\mathrm{O}), 1599(-\mathrm{C}=\mathrm{C}-), \quad 3108(=\mathrm{C}-\mathrm{H}), \quad 1678(\mathrm{C}=\mathrm{N})$,
1058 (C-O-N); ${ }^{1} \mathrm{HNMR}\left(90 \mathrm{MHz}, \mathrm{CDCl}_{3} / \mathrm{TMS}\right): 8.18-$ $8.22(\mathrm{~m}, \mathrm{ArH}), 3.67(\mathrm{~d}, 2 \mathrm{H}), 6.29(\mathrm{~m}, 1 \mathrm{H}), 4.96-5.04$ $(\mathrm{d} / \mathrm{d}, 2 \mathrm{H}), 2.49$ (s, 3H); ${ }^{13} \mathrm{CNMR}\left(22.5 \mathrm{MHz}, \mathrm{CDCl}_{3} /\right.$ TMS):174.9, 62.16, 160.53, 132.88, 131.09, 129.15, $128.38,126.87,109.92,42.30,12.82$.

2.2e 1-(3-(2,6-Dichlorophenyl)-5-methylisoxzol-4-yl) but-3-en-1-one (table 4 entry 7) $3 g: \quad \mathrm{IR}\left(v_{\max }, \mathrm{KBr}\right.$ Pellet in $\left.\mathrm{cm}^{-1}\right)$ : $1712(-\mathrm{C}=\mathrm{O}), \quad 1637(-\mathrm{C}=\mathrm{C}-), 3060$ (=C-H), $1645(\mathrm{C}=\mathrm{N}), 1069$ (C-O-N), $717(\mathrm{C}-\mathrm{Cl}){ }^{1} \mathrm{HNMR}$ (90 MHz, $\left.\mathrm{CDCl}_{3} / \mathrm{TMS}\right)$ : 7.78-8.34 (m, ArH), 3.97 (d, $2 \mathrm{H}), \quad 6.48(\mathrm{~m}, 1 \mathrm{H}), 4.23-4.54(\mathrm{~d} / \mathrm{d}, 2 \mathrm{H}), 2.57 \quad(\mathrm{~s}, 3 \mathrm{H})$; ${ }^{13} \mathrm{CNMR} \quad\left(22.5 \mathrm{MHz}, \mathrm{CDCl}_{3} / \mathrm{TMS}\right): 175.74, \quad 162.12$, 158.67, 134.65, 131.97, 128.10, 109.93, 42.29, 12.80.

$2.2 \mathrm{f}$ 1, 4-Diphnyl-but-3-en-1 one (table 4 entry 11) $4 \boldsymbol{a}:{ }^{13}$ IR $\left(v_{\max }, \mathrm{KBr}\right.$ Pellet in $\left.\mathrm{cm}^{-1}\right): 1450,1598$, 1679, 3062; ${ }^{1} \mathrm{HNMR}$ (90 MHz, $\left.\mathrm{CDCl}_{3} / \mathrm{TMS}\right): 3.89(2 \mathrm{H}$, br S), 5.82-6.09 (1H, m), 5.09-5.39 (1H, d/d), 7.25-8.4 (ArH,m); ${ }^{13} \mathrm{C}$ NMR $\left(22.5 \mathrm{MHz}, \mathrm{CDCl}_{3} / \mathrm{TMS}\right): \delta 171.94$, $133.77,130.2,129.4,128.41,105.07,42.28$

$2.2 \mathrm{~g}$ 1-(2-Chloro phenyl)-4-phenyl-but-3-en-1-one (table 4 entry 12)4b: IR $\left(v_{\max }, \mathrm{CHCl}_{3}\right.$ in $\left.\mathrm{cm}^{-1}\right): 725$, 1249, 1445, 1593, 1714, 3040; ${ }^{1} \mathrm{HNMR}\left(90 \mathrm{MHz}, \mathrm{CDCl}_{3}\right.$ / TMS): $3.53(2 \mathrm{H}$, br S), $6.33-6.53(1 \mathrm{H}, \mathrm{m}), 5.11(1 \mathrm{H}$, d/d), 7.32-7.83 (ArH, m); ${ }^{13} \mathrm{C} \mathrm{NMR}\left(22.5 \mathrm{MHz}, \mathrm{CDCl}_{3} /\right.$ TMS): $165.00,132.98,132.87,132.01,130.84,130.51$, $130.00,129.4,128.00,127.13,126.18,125.54,44.87$.

2.2h 1-Furan-2yl-4-phenyl-but-3en-1-one (table 4 entry 13)4c: IR ( $v_{\max }, \mathrm{CHCl}_{3}$ in $\left.\mathrm{cm}^{-1}\right): 1014,1116,1473$, 1581, 1701, 2877, 3016; ${ }^{1} \mathrm{HNMR}$ (90 MHz, $\mathrm{CDCl}_{3} / \mathrm{TMS}$ ): $3.85(2 \mathrm{H}, \mathrm{br} \mathrm{S}), 6.08$ (1H, m), 6.26-6.41 (1H, dd), 6.536.71 (3H, m), 7.31-7.67 (ArH, m); ${ }^{13} \mathrm{C} \mathrm{NMR} \mathrm{(22.5} \mathrm{MHz,}$ $\mathrm{CDCl}_{3}$ /TMS): $160.34,146.09,144.07,135.41,133.51$, $1238.08,126.16,124.38,118.91,111.16,44.87$

$2.2 \mathrm{i}$ 2-Methyl-6-phenyl-hex-5-en-3-one (table 4 entry 14)4d: IR ( $v_{\max }, \mathrm{CHCl}_{3}$ in $\left.\mathrm{cm}^{-1}\right): 1438,1593,1724$, 
3020; ${ }^{1} \mathrm{HNMR}\left(90 \mathrm{MHz}, \mathrm{CDCl}_{3} / \mathrm{TMS}\right): 1.13-1.21(6 \mathrm{H}$, d), 2.13-2.55 $(1 \mathrm{H}, \mathrm{m}), 3.85(2 \mathrm{H}, \mathrm{br} \mathrm{S}), 6.16(1 \mathrm{H}, \mathrm{m})$, 6.26-6.41 (1H, dd), 6.26-6.54 (1H, dd), 6.54-6.71 (ArH, m), 7.30-7.38 (ArH, m); ${ }^{13} \mathrm{CNMR}(22.5 \mathrm{MHz}$, $\mathrm{CDCl}_{3}$ /TMS): 181.64, 135.63, 133.81, 128.33, 127.94, $126.39,125.00,124.3,45.07,31.98,23.18,21.75,18.47$.

\section{Results and discussions}

In a typical experiment, allylhalide and acid chloride were mixed in the presence of catalytic amount of copper nano ferrite in stoichiometric portions using tetrahydrofuran as solvent and stirred at room temperature. The completion of the reaction was monitored by thin-layer chromatographic technique ( $n$-hexane and ethyl acetate as elute). In our initial efforts to optimize the reaction condition, we screened various solvents like tetrahydrofuran, diethylether, dichloromethane and acetonitrile for this reaction. We found the reaction was efficient in tetrahydrofuran compared to the other solvents tested. The results are listed in table 1. From table 1, it is clearly evident that a significant decrease in yields and longer reaction times are noted for the solvents other than THF, whereas in the presence of tetrahydrofuran the yields are promising and shorter reaction times are noted.

After completion of the reaction, the catalyst was recovered by magnetization and washed with diethyl ether and the recovered catalyst was reused for few more cycles. During washing with the solvent, it was clearly evident that there was no leaching of catalyst and was confirmed by performing the reaction with the filtrate. Atomic absorption spectroscopy was employed to determine the copper content of copper ferrite nano particles and it was found to be $27.3 \%$. The leaching of metal after three cycles was found to be $0.156 \%$. From our investigations, we observe that nano catalyst shows excellent to good reactivity with promising yields even for the next three cycles in the same reaction. Since, there was no observable loss in the yield percentage; the further reusability of nano catalyst was not needed. The results are listed in table 2 .

Table 1. Allylation of acid chlorides under different solvent systems.

\begin{tabular}{lcccc}
\hline S.No & Catalyst & Solvent & Time(h) & Yield* \\
\hline 1 & $\mathrm{CuFe}_{2} \mathrm{O}_{4}$ & $\mathrm{THF}$ & 1.5 & 95 \\
2 & $\mathrm{CuFe}_{2} \mathrm{O}_{4}$ & $\left(\mathrm{C}_{2} \mathrm{H}_{5}\right)_{2} \mathrm{O}$ & 3.5 & 78 \\
3 & $\mathrm{CuFe}_{2} \mathrm{O}_{4}$ & Dichloromethane & 6 & 63 \\
4 & $\mathrm{CuFe}_{2} \mathrm{O}_{4}$ & MeCN & 12 & trace \\
\hline
\end{tabular}

*Isolated yields
Table 2. Reusability of nano catalyst.

\begin{tabular}{lcc}
\hline S.No & Catalyst recovery $^{\mathrm{a}}(\%)$ & Yeild $^{\mathrm{b}}(\%)$ \\
\hline 1 & - & 95 \\
2 & 97 & 89 \\
3 & 86 & 82 \\
4 & 80 & 78 \\
\hline
\end{tabular}

${ }^{\mathrm{a} C}$ Catalyst recovered by membrane filtration and washed with diethyl ether and then by distilled water

${ }^{\text {b}}$ Yields compared to isolated products

From table 3, it is noticed that in some reactions the catalyst needs co-catalysts/additives. Some reactions need the acidic/basic workup to get the product. But here in this nano sized copper ferrite catalyst; there is no need of additives, ligands, co-catalysts and no need of activation for its reusability. The notable advantages of this method are (i) lesser reaction times and (ii) reusability than the earlier reported methods.

The allyl bromide and cinnamyl chloride reacted with a wide variety of 10 acid chlorides under the above optimized conditions and the results are summarized in table 4. From the table 4, it is observed that when the reaction proceeded with aliphatic long chain acid chlorides, the formation of allyl ketone was not found. It appears that neither electronic effects, nor steric effects are important factors in acylation of allyl halides by nano catalyst. All the acylation reactions proceed with allylic rearrangement, ${ }^{14}$ so that the double bond was removed from the conjugation. The mechanism, in which electrophillic attack of nano ferrite occurs at the $\gamma$ carbon atom of allylic moiety, generated in situ, will react with the acyl halides resulting in the title compounds. The formation of stable allyl ketone is confirmed by IR and NMR spectral studies. In ${ }^{1} \mathrm{HNMR}$ spectra, the chemical shift at $\delta$ 4.01-5.39, as doublet of doublet, confirms the presence of formation of stable olefinic bond. This indicates that allylation takes place at carbonyl carbon without any prototropic rearrangement.

Table 3. Reaction times by different catalysts for the allylation of acid chlorides.

\begin{tabular}{llc}
\hline S.No & Catalyst & Time*(h) \\
\hline 1 & $\mathrm{Ni}(\mathrm{Cod})_{2}{ }^{15}$ & 15 \\
2 & $\mathrm{Zn}^{9}$ & 3 \\
3 & $\mathrm{Cd}^{8}$ & 3 \\
4 & $\mathrm{In}^{10}$ & 3 \\
5 & $\mathrm{BuSnCl}_{2}+$ Additive $^{16}$ & 2 \\
6 & $\mathrm{CuFe}_{2} \mathrm{O}_{4}$ & 1.5 \\
\hline *Reaction times & related to the synthesis of allyl phenyl \\
ketone &
\end{tabular}


Table 4. Synthesis of allyl ketones using copper ferrite nano particles.

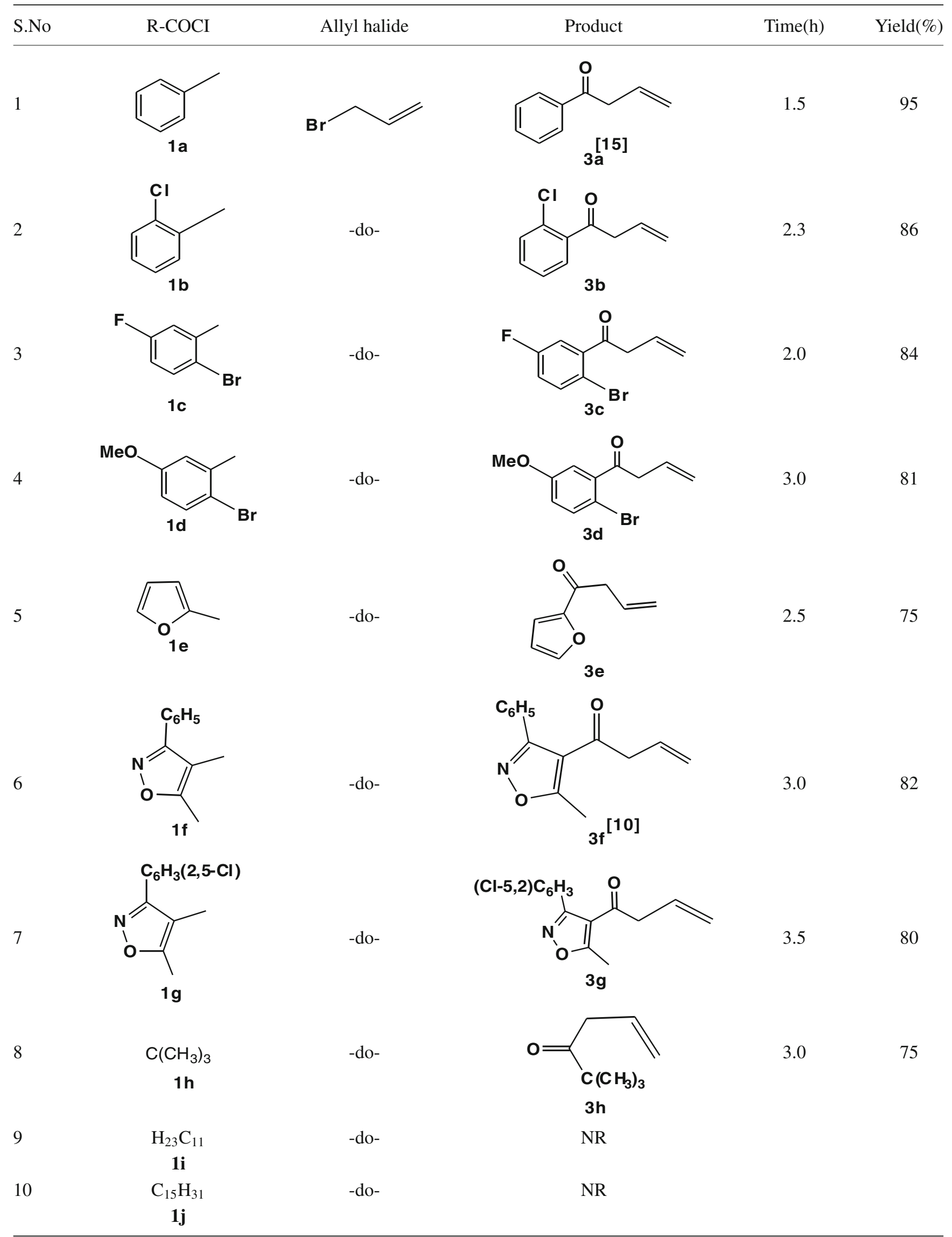


Table 4. (continued)

(1) Yield(\%)

*Yields compared to isolated products and characterized by IR and NMR studies compared with authentic samples NR: No reaction

From ${ }^{13} \mathrm{CNMR}$ data the chemical shift for carbonyl carbon is observed at $162-175 \mathrm{ppm}$ and 132.5 $143.92 \mathrm{ppm}$ corresponds to the $\beta$ carbon and chemical shift at $105.07-111.82 \mathrm{ppm}$ for the $\gamma$ carbon. This indicates the tolerance to the double bond. The results with allyl bromide encouraged us to extend the reaction with cinnamyl chloride. The synthetic route is presented in scheme 2. The reaction was done under above said optimized conditions. The results are listed in table 4.

XRD studies were carried out to the above nano ferrite and XRD spectrum is presented in figure 1. From the XRD data, it is observed that the copper ferrites are spinal crystals. From the XRD data, the size of the copper ferrite particles is calculated by using sheerer

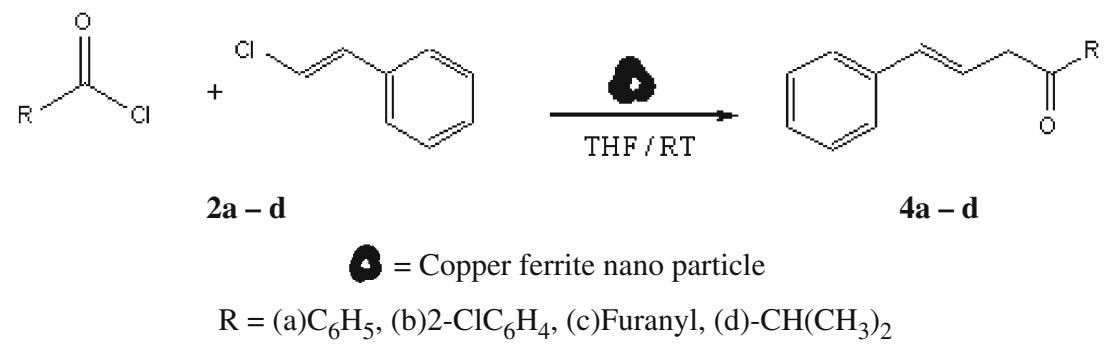

Scheme 2. Synthesis of $\beta, \gamma$-unsaturated ketone using cinnamyl chlorides. 


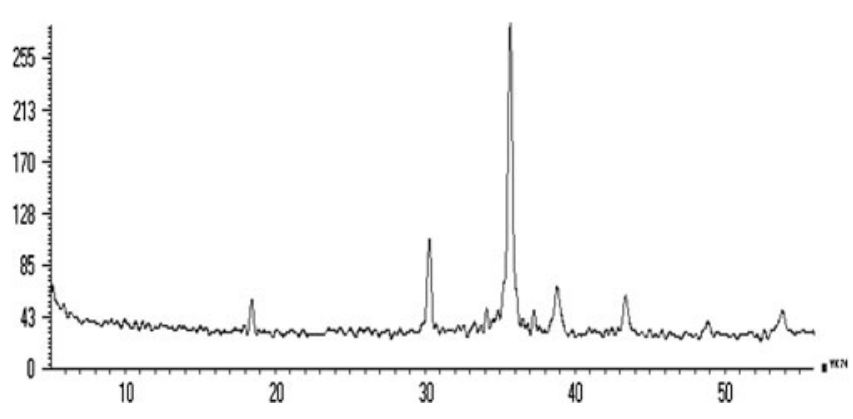

Figure 1. XRD spectrum of $\mathrm{CuFe}_{2} \mathrm{O}_{4}$ at $600^{\circ} \mathrm{C}$.

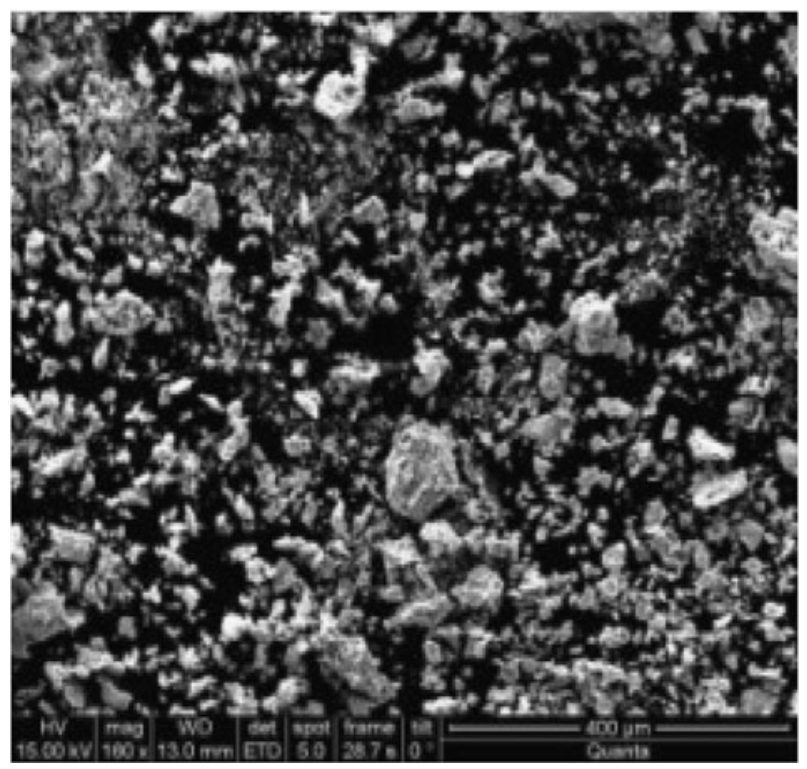

Figure 2. SEM image $\mathrm{CuFe}_{2} \mathrm{O}_{4}$.

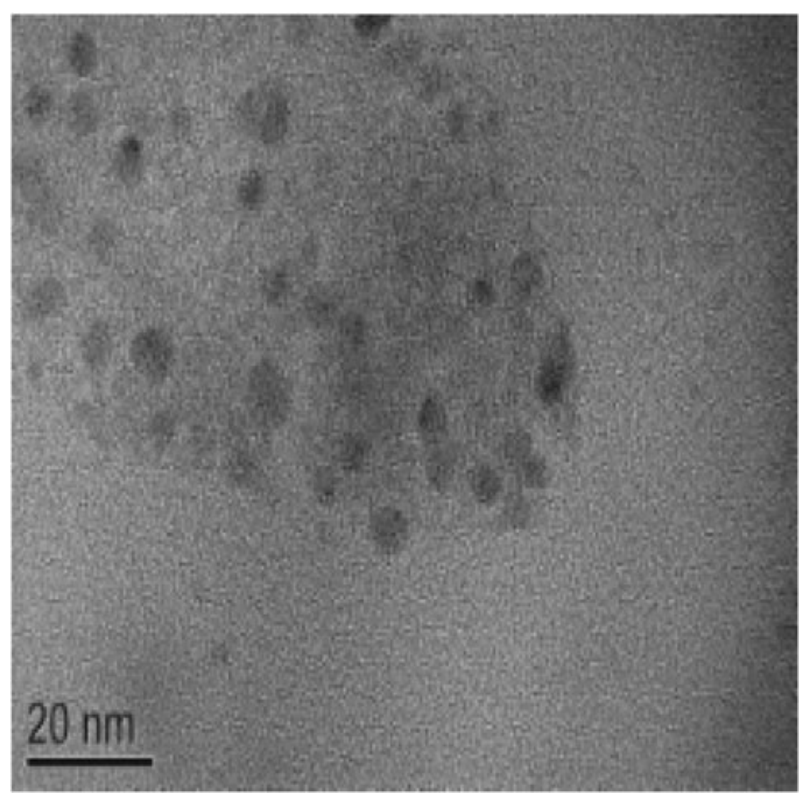

Figure 3. TEM image of $\mathrm{CuFe}_{2} \mathrm{O}_{4}$. formulae and particle size is found to be $20 \mathrm{~nm}$. This shows that the synthesized powder has nano size crystalline. The scanning electron microscope studies are carried out on the copper ferrite sample at $600^{\circ} \mathrm{C}$, and it is presented in figure 2. The TEM image was recorded and presented in figure 3. The lump size with irregular morphology was observed and it was found at $400 \mu \mathrm{m}$ at $600^{\circ} \mathrm{C}$. From the above study, we observed less number of pores with smaller lump size, resulting fine grained microstructure with respect to ferrites.

\section{Conclusions}

In conclusion, we report here for the first time an efficient protocol in the synthesis of $\beta, \gamma$-unsaturated ketones using copper ferrite nano material. The notable advantages are less expensive, heterogeneous reusable catalyst; mild reaction conditions, high yields of products, shorter reaction times, no isomerization during the reaction and easy workup.

\section{Acknowledgements}

The authors are thankful to Defence Research and Development Organization (DRDO), New Delhi for providing financial assistance. The authors are also grateful to the Committee On Strengthening Infrastructure for Science \& Technology (COSIST) Labs, Andhra University for providing spectral data.

\section{References}

1. (a) Yoon T J, Lee W, Oh Y S and Lee J K 2003 New J. Chem. 27 227; (b) Stevens P D, Fan J, Gardimalla H M R, Yen M and Gao Y 2005 Org. Lett. 7 2085; (c) Stevens P D, Li G, Fan J, Yen M and Gao Y 2005 Chem. Commun. 4435

2. Bell A T 2003 Science 2991688

3. Kantam M L, Yadav J, Soumi L, Srinivas P, Sreedhar B and Figueras F 2009 J. Org. Cheem. 744611

4. Demuth M and Mikhail G 1989 Synthesis 1989(3) 145

5. (a) Monti S A and White G L 1975 J. Org. Chem. 40 215; (b) Hoffman H M R and Tsushima T 1977 J. Am. Chem. Soc. 99 6008; (c) Beak P and Berger K R 1980 J. Am. Chem. Soc. 102 3848; (d) Earnshaw C, Torr R S and Warren S S 1983 J. Chem. Soc. Perkin Trans. 12893

6. (a) Groves J K 1972 Chem. Soc. Rev. 1 73; (b) Noyce D S and Evett M 1972 J. Org. Chem. 37, 394; (c) Aumiller J C and Whittle J A 1976 J. Org. Chem. 41 2959

7. (a) Hosomi A, Hashimoto H and Sakurai H 1978 J. Org. Chem. 43 2551; (b) Hayashi T, Konishi M, Ito H and Kumuda M 1982 J. Am. Chem. Soc. 104 4962; (c) Labadie J W, Tueting D and Stille J K 1983 J. Org. 
Chem. 48 4634; (d) Sato T, Kawara T, Nishizawa A and Fujisawa T 1980 Tetrahedron Lett. 21 3377; (e) Hegedus I S, Kendall P M, Lo S M and Sheats J R 1975 J. Am. Chem. Soc. 97 5448; (f) Cahiez G and Laboue B 1989 Tetrahedron Lett. 30 7369; (g) Kasatkin A N, Kulak A N and Tolstikov G A 1988 J. Organomet. Chem. 23 346; (h) Larock R C and Lu Y 1993 J. Org. Chem. 58 2846

8. Bipul B, Anima B, Dipak P and Jagir S S 1996 Tetrahedron Lett. 37(50) 9087

9. Ranu B C, Majee A and Das A R 1995 Tetrahedron Lett. 364885

10. Yadav J S, Srinivas D, Reddy G S and Himabindu K 1997 Tetrahedron Lett. 36(50) 8745
11. Murhy Y L N, Kaiviswanath I V, Kondalarao T and Rajendrasingh 2009 J. Chem. Chem. Eng. 36

12. Curran D P and Kim B H 1986 Synthesis 1986(4) 312

13. Paira M, Mandal S K and Roy S C 2010 Indian J. Chem. B 49573

14. (a) Hegedus L S, Kendall P M, Lo S M and Sheats J R 1975 J. Am. Chem. Soc. 97 5448; (b) Cahiez G and Laoue B 1989 Tetrahedron Lett. 30 7369; (c) Kasatkin A N, Kulak A N and Tolstikov G A 1988 J. Organomet. Chem. 34623

15. MakotoOnaka, ToshioGoto, Teruaki and Mukaiyama 1979 Chem. Lett. 8(12) 1483

16. Katsunori Yano, Akio Baba and Mastuda H 1991 Chem. Lett. 20(7) 1181 